\title{
Defining and Measuring Compliance With Oral Appliance Therapy
}

Reza Radmand, DMD'; Harmeet Chiang, BDS, DDS, MS, FAGD²; Massimiliano Di Giosia, DDS ${ }^{3}$; Maria Therese Galang-Boquiren, DMD, MS 4 ; Rosemarie Rohatgi, DMD 5 ; David Silk, DDS ${ }^{6}$; Olivier M. Vanderveken, MD, PhD; Michael Adame, DDS ${ }^{8}$

${ }^{1}$ Chair, Brigham and Women's Hospital, Division of Sleep Medicine, Harvard Medical School, Boston, Massachusetts; ${ }^{2}$ Virginia Commonwealth University, Richmond, Virginia; ${ }^{3}$ University of North Carolina, Chapel Hill, North Carolina; ${ }^{4}$ University of IllinoisChicago, Chicago, Illinois; ${ }^{5}$ San Diego Sleep Therapy, San Diego, California; ${ }^{6}$ Private Practice, Solon, Ohio; ${ }^{7}$ Department ENT, Antwerp University Hospital, Translational Neurosciences, Faculty of Medicine and Health Sciences, University of Antwerp, Antwerp, Belgium; ${ }^{8}$ Board Liaison, Adame Dental Sleep Medicine

\section{INTRODUCTION}

Oral appliance therapy (OAT) is a proven, effective treatment for obstructive sleep apnea (OSA); however, it can only be effective when it is used, which is why compliance - "the extent to which a patient's behaviors match the prescriber's recommendations" ${ }^{\prime}$ - is a necessary component of OAT.

Over the years, qualified dentists have individually used various metrics to define a patient's compliance. Currently, there is no standardized definition for oral appliance therapy (OAT) compliance.

In developing a standardized definition for OAT compliance, the task force recognizes that compliance involves two components - the number of hours of sleep and the number of hours of oral appliance (OA) use. The prescriber recommendations for OAT are that patients sleep a minimum of 7 hours per night and wear the appliance for the duration of their sleep every night. Although it is not always possible for patients to get the recommended amount of sleep, OAs are most therapeutically effective when patients sleep 7 hours or more, ${ }^{2}$ so qualified dentists should educate patients on the importance of proper sleep duration and encourage patients to get at least 7 hours of sleep each night. When treating patients with OSA, the qualified dentist becomes a frequent point of contact with the patient and plays an important role in encouraging habits that will increase the chances of OAT success.

Recognizing the above ideas, it is recommended that the patient sleep a minimum of seven (7) hours per night and wear the appliance for the duration of their sleep every night. OAT compliance is defined as the appliance being worn for a minimum of $\geq 80 \%$ per night, starting when the $O A$ is placed in the mouth and ending when the OA is removed from the mouth, $\geq 5$ nights per week.

Supported methods for measuring these parameters include questionnaires, sleep diaries, and microsensors.

Patient progress is a vital consideration in OAT compliance and can often be improved using positive encouragement. Additionally, the dentist should be attentive to patient comfort and any potential side effects related to $\mathrm{OAT}^{3}$ A patient may be categorized as fully compliant, improving over time, or noncompliant. Given the long-term consequences of untreated OSA, patients deemed noncompliant after 1 year of use should be referred to their physician with a recommendation for alternative treatments.

\section{DEFINITION OF OAT COMPLIANCE DISCUSSION}

When developing this definition, the task force considered how compliance is defined in the very limited scientific literature, the accepted definition used to measure positive airway pressure compliance, and the clinical knowledge of the qualified dentist. The American Academy of Sleep Medicine recommends that adults sleep 7 or more hours per night for optimal health. ${ }^{4}$ Although this recommendation is optimal, the task force considered that the nightly hours of sleep vary substantially by patient. ${ }^{5}$ When determining the minimum necessary daily wear time for compliance, the task force acknowledged that an OA is most therapeutically effective when the patients sleeps 7 or more hours per night and the OA is worn for the duration of the patient's sleep time. The task force acknowledges that many patients are simply unable to initially sleep 7 hours per night, but it is necessary that qualified dentists provide the education to encourage patients to get this amount of sleep and that this be factored into OAT compliance.

Studies have indicated that higher rates of adjusted compliance (mean appliance wear time divided by total sleep time) are associated with reduction in disease. Dieltjens and colleagues ${ }^{6}$ indicated that among patients using OAT, adjusted compliance (objectively measured) was $86.1 \%$, with therapeutic efficacy at $63.7 \%$ and mean disease alleviation (MDA) at $54.9 \%$. Another study found the adjusted compliance to be $91.2 \%$, the treatment efficacy to be $56 \%$, and the MDA to be $51.1 \% .^{7}$ Thus, higher rates of compliance are associated with good levels of treatment effectiveness.

When determining the appropriate weekly wear time, 
the task force found an ample number of studies that defined compliance as wearing the appliance at least 5 nights per week or $70 \%$ of nights (which translates to 4.9 nights per week, rounded up to 5) ${ }^{8-15}$ Although it is important to note that many of these studies also defined nightly wear time as at least 4 hours per night, these studies indicate that a wear time of 5 nights per week can be effective in MDA and reduction of signs and symptoms, such as snoring. ${ }^{14,16}$ Thus, the task force determined that a patient is compliant if they use the OA at least 5 nights per week; however, qualified dentists should strongly encourage the patient to use the OA every night.

For this definition, the start time is when the patient inserts the OA and lies down to sleep and ends when the patient removes the OA. Although this does not truly measure the hours of sleep, it does allow patients to be involved in tracking their compliance. Studies have indicated higher compliance when patients have a sense of ownership in their own care. ${ }^{17}$

The task force also determined that patient compliance will improve if positive reinforcement is provided. A definition of compliance that is both practical for patients and also increases their chances of treatment success is needed. Therefore, the task force determined that classifying patient compliance as fully compliant, improving over time, or noncompliant is appropriate. "Improving over time" was thought to be a positive motivating factor for the patient. The dental practitioner should use their best judgment and expertise to determine the appropriate category for their patient. Given the longterm consequences of untreated OSA, if a patient is noncompliant for 1 year with any component of the definition, the patient needs to consider alternative therapies and should be referred to their physician.

\section{METHODS FOR MEASURING COMPLIANCE DISCUSSION}

\section{Supported Methods}

\section{SUBJECTIVE METHODS:}

With the advent of objective compliance monitoring devices, some studies have argued that objective methods are ideal because they avoid the potential bias of patient self-report. ${ }^{18}$ Additionally, one study indicated that selfreport can slightly overestimate appliance wear time when compared to objective compliance measurement. ${ }^{6}$ Nevertheless, other studies have indicated that objective and subjective reporting of compliance is highly similar in accuracy. ${ }^{7,8,19,20}$ Thus, the task force determined that questionnaires and sleep diaries were appropriate subjective methods for measuring OA compliance.

\section{Questionnaires}

Questionnaires were determined to be appropriate for clinical use to measure compliance. These are forms that are completed at follow-up visits. They are simple to use and administer. Currently, there is no standardized, validated questionnaire to measure $\mathrm{OA}$ compliance. However, at minimum, the questionnaire should include questions to assess patients' nocturnal and daytime symptoms (snoring, witnessed apneas, gasping, sleepiness). In the adult population, the Epworth Sleepiness Scale and Berlin and STOP-BANG questionnaires are the most used. ${ }^{21-23}$ The questionnaire also must gather information regarding how many days a week the patient uses the OA on average, average sleep duration, and what time the patient commonly inserts the $\mathrm{OA}$ and removes the OA.

\section{Sleep Diaries}

Sleep diaries were determined to be appropriate for clinical use to measure compliance. They are simple to use and administer. Currently, there is no standardized, validated sleep diary to measure compliance; however, samples of sleep diaries are readily available for patient use. Patients should be instructed to complete the sleep log daily. At minimum, the patient should track their sleep duration, as well as the time the OA was inserted and when it was removed each night. The patient should also indicate if they are experiencing any nocturnal or daytime symptoms (e.g., snoring, witnessed apneas, gasping, sleepiness) to provide the qualified dentist with an indication of any potential issues with therapeutic effectiveness.

\section{OBJECTIVE METHODS:}

\section{Microsensors}

The task force determined that microsensors are also appropriate for measuring OA compliance. Microsensors are usually embedded in the OA and measure compliance in a variety of ways. Some measure temperature to determine when the appliance is being worn by the patient. 9, 10, 14, 16, 24 For example, one design of thermosensor operates by recording the $\mathrm{OA}$ as being in use every time it reaches a temperature of $35^{\circ} \mathrm{C}$ or higher. The thermosensor can take a measurement every 15 minutes for 100 consecutive days. ${ }^{10,14,16}$ One study determined these temperature data loggers were "only minimally cytotoxic and are effective for measuring compliance with the use of OAs". ${ }^{24}$ Other microsensors use radiofrequency identification to transfer compliance data to a computer. ${ }^{8,19}$

Advantages of microsensors are that they objectively monitor compliance and tend to be accurate when compared to subjective report, ${ }^{19}$ they can often connect to 
data cloud services, have a long battery life ( 2 years), are biocompatible, ${ }^{24}$ and are efficient with memory and power, which can be beneficial for long-term studies of compliance. Disadvantages can include failure of seals and battery contamination as well as possible lower amounts of data storage (6 months). Thermosensors can also be manipulated by placing the appliance in a temperature medium at or above $35^{\circ} \mathrm{C}$, mimicking the core minimum temperature of the body. Additionally, patients may be uncomfortable with their data being transmitted to the clinician without their knowledge. At this stage, microsensors do not calculate sleep duration, so it is important for dentists to gather information from the patient about average sleep duration.

\section{Unsupported Methods}

The task force also determined that some of the methods reviewed are not appropriate for measuring a patient's compliance:

- Clinical evaluation by a specialist (clinician estimation of the time of wear based on evaluation of appliance condition and patient report of their symptomology) was determined to be inappropriate for clinical use. This method may provide an inaccurate estimate of a patient's compliance with treatment. ${ }^{18}$

- A patient's compliance cannot be determined by evaluating a patient's personality traits. The evidence is too limited to be deemed appropriate. However, patient personality traits may be better utilized in predicting future adherence and personalizing patient education. ${ }^{25}$

- Tooth microphones that were attached to the OA and traversed the lips to be connected to a computer $^{26}$ and the use of fiberoptic sensors that monitored the presence of the OA through pressure and temperature changes were evaluated. Both only had one proof-of-concept paper describing the method and were not currently appropriate ways to measure compliance in the clinical setting.

- The task force also considered the use of pulse oximetry ${ }^{9,24,27}$ and pneumatic actuators ${ }^{27}$ to measure compliance. However, the articles reviewed merely discussed these tools in the context of appliance titration and gave no proof for their usefulness for compliance measurement.

\section{Forthcoming Technologies}

The task force also indicated that there are a number of potential future devices that may aid in the measurement of OAT compliance. For example, consumer sleep technologies (apps and wearables that measure sleeprelated metrics) are becoming more ubiquitous. ${ }^{28}$ In the future, these technologies could be leveraged for patients to easily measure compliance, including sleep duration, at home. For example, mobile applications could be designed to track time in bed as well as daily wear time.

\section{METHODOLOGY}

\section{Consensus Conference Process}

The American Academy of Dental Sleep Medicine Board of Directors selected seven experts to participate in this task force, all of whom have extensive knowledge of dental sleep medicine. None of these task force members declared conflicts of interest that were relevant to this topic.

The task force used a modified version of the RAND/UCLA Appropriate Method to conduct the consensus conference. ${ }^{29}$ The task force took into consideration their own clinical experience, relevant literature on the topic, clinical practicality, and patient preference when making their decisions.

\section{Literature Search and Review}

A literature search of PubMed was conducted using permutations of relevant search terms. Additionally, the bibliographies of pertinent articles were also reviewed for any other key articles.

Search terms related to treatment included: oral, intraoral, dental, orthodontic(s), mandibular, tongue retaining, tongue stabilizing, occlusal, titratable/titrated, appliance(s), splint(s), device(s).

Search terms related to disease included: sleep apnea, sleep apnea syndromes, sleep-related breathing disorder(s), sleep-disordered breathing, snoring.

Search terms related to compliance included: compliance, adherence.

Commentaries, biographies, editorials, news/newspaper articles, addresses, letters, and case reports were also excluded from the original search. Papers were not included if they only addressed long-term compliance. After all irrelevant articles were excluded, the final set of articles totaled 57. An additional two articles were recommended by task force members for review for a final count of 59. The articles were divided among the task force members, based on article topic.

\section{Consensus Conference}

A virtual conference was held on October 16, 2020. The conference was conducted via video call due to travel difficulties related to COVID-19. Prior to the conference, the task force was sent a comprehensive list of possible elements for a compliance definition and possible methods to measure compliance. This list was based on the literature and task force input. 
For the first round of voting, task force members were asked to independently rate each definition element and measurement method on a scale of 1 to 9 , with 1 indicating that the element or method was inappropriate and 9 indicating that it was appropriate. The task force was instructed to vote based on their clinical expertise and the literature reviewed. Prior to the conference, task force members were also asked to record presentations on the literature reviewed. Each task force member watched these presentations prior to the conference.

During the conference, task force members discussed the literature and their clinical experiences and then voted a second time on each of the definition elements and compliance measurement methods. For the discussion on the definition, a third vote was held. Elements on which the task force did not reach consensus were eliminated. A yes/no vote was held to determine the final elements to include in the definition. For the discussion on measurement methods, a second vote was held and if consensus was not achieved, a third vote was held.

According to RAND/UCLA rules, unanimity is not required to reach consensus. ${ }^{29}$ Rather, for a group of this size, five of seven task force members had to be in agreement for consensus to be reached.

\section{LIMITATIONS AND RECOMMENDATIONS}

As with all consensus documents, these recommendations rely on the clinical expertise of the task force in conjunction with literature. Although a thorough search of the literature was conducted, it could not be conducted as a systematic review. Thus, the task force acknowledges that some literature may not have been included. In addition, the studies reviewed also had limitations as well. Many had small sample sizes, were not randomized, had no control groups, and had short followup periods with patients. Furthermore, many articles did not directly test the definition of compliance or measurement methods.

The task force recommended that future research be conducted regarding compliance with OAT. Specifically, the task force made the following recommendations:

- Validated and standardized questionnaires and sleep diaries for OA compliance should be evaluated and tested.

- The definition of OA compliance, as stated in this paper, should be directly tested to determine its effect on treatment success.

- Larger studies should be conducted that have long-term follow-up, randomization, and control groups.

- Technologies and methods for which there was limited evidence (personality traits, tooth microphones, fiberoptic sensors) should continue to be tested. The technology should continue to be refined and optimized (eg, wireless technology, pulse oximetry).

- Forthcoming technologies should be tested for potential applicability to $\mathrm{OA}$ compliance.

\section{CITATION}

Radmand R, Chiang H, Di Giosia M, et al. Defining and measuring compliance with oral appliance therapy. J Dent Sleep Med. 2021;8(3).

\section{REFERENCES}

1. Chakrabarti S. What's in a name? Compliance, adherence and concordance in chronic psychiatric disorders. World J Psychiatry. 2014;4(2):30. doi:10.5498/wjp.v4.i2.30

2. Sutherland K, Phillips CL, Cistulli PA. Efficacy versus effectiveness in the treatment of obstructive sleep apnea: CPAP and oral appliances. J Dent Sleep Med. 2015;2(4). doi:10.15331/jdsm.5120

3. Levine M, Bennett KM, Cantwell MK, Postol K, Schwartz DB. Dental Sleep Medicine Standards for Screening, Treating and Managing Adults with Sleep-Related Breathing Disorders Standards of Practice Committee of the American Academy of Dental Sleep Medicine. J Dent Sleep Med. 2018;5(3).

4. Watson NF, Badr MS, Belenky G, et al. Recommended amount of sleep for a healthy adult: A joint consensus statement of the American Academy of Sleep Medicine and Sleep Research Society. Sleep. 2015;38:843-844. doi:10.5665/sleep.4716

5. Liu Y, Wheaton AG, Chapman DP, Cunningham TJ, Lu H, Croft JB. Prevalence of healthy sleep duration among adults - United States, 2014. MMWR Morb Mortal Wkly Rep. 2016;65:137-141. DOI: http://dx.doi.org/10.15585/mmwr.mm6506a1external icon.McGown AD, Makker HK, Battagel JM, L'Estrange PR, Grant HR, Spiro SG. Long-term use of mandibular advancement splints for snoring and obstructive sleep apnoea: A questionnaire survey. Eur Respir J. 2001;17(3):462-466. doi:10.1183/09031936.01.17304620

6. Dieltjens M, Braem MJ, Vroegop AVMT, et al. Objectively measured vs self-reported compliance during oral appliance therapy for sleepdisordered breathing. Chest. 2013;144(5):1495-1502. doi:10.1378/CHEST.13-0613

7. Vanderveken OM, Dieltjens M, Wouters K, De Backer WA, Van De Heyning PH, Braem MJ. Objective measurement of compliance during oral appliance therapy for sleep-disordered breathing. Thorax. 2013;68(1):91-96. doi:10.1136/thoraxjnl-2012-201900

8. Mullane S, Loke W. Influence of short-term side effects on oral sleep appliance compliance among CPAP-intolerant patients: An objective monitoring of compliance. J Oral Rehabil. 2019;46(8):715-722. doi:10.1111/joor.12802

9. Yamamoto U, Nishizaka M, Tsuda H, Tsutsui H, Ando S. Crossover comparison between CPAP and mandibular advancement device with adherence monitor about the effects on endothelial function, blood pressure and symptoms in patients with obstructive sleep apnea. Heart Vessels. 2019;34(10):1692-1702. doi:10.1007/s00380-019-01392-3

10. de Ruiter MHT, Benoist LBL, de Vries N, de Lange J. Durability of treatment effects of the Sleep Position Trainer versus oral appliance therapy in positional OSA: 12-month follow-up of a randomized controlled trial. Sleep Breath. 2018;22(2):441-450. doi:10.1007/s11325-017-1568-4

11. Friedman M, Hamilton C, Samuelson CG, et al. Compliance and efficacy of titratable thermoplastic versus custom mandibular advancement devices. Otolaryngol Head Neck Surg. 2012;147(2)::379-386. doi:10.1177/0194599812439683

12. Lee $\mathrm{WH}$, Wee $\mathrm{JH}$, Lee $\mathrm{CH}$, et al. Comparison between mono-bloc and 
bi-bloc mandibular advancement devices for obstructive sleep apnea. Eur Arch Otrorhinolaryngol. 2013;270(11):2909-2913. doi:10.1007/s00405-013-2417-0

13. Wee JH, Lim JH, Gelera JE, Rhee C-S, Kim J-W. Comparison of success criteria based on long-term symptoms and new-onset hypertension in mandibular advancement device treatment for obstructive sleep apnoea: observational cohort study. BMJ Open. 2018;8(5):e021644. doi:10.1136/bmjopen-2018-021644

Benoist L, de Ruiter M, de Lange J, de Vries N. A randomized, controlled trial of positional therapy versus oral appliance therapy for position-dependent sleep apnea. Sleep Med. 2017;34:109-117. doi:10.1016/j.sleep.2017.01.024

15. Wang TC, Tsou YA, Wu YF, et al. Treatment success with titratable thermoplastic mandibular advancement devices for obstructive sleep apnea: A comparison of patient characteristics. Ea, Nose Throat J. 2017;96(3):E25-E25. doi:10.1177/014556131709600322

Dieltjens M, Verbruggen AE, Braem MJ, et al. Determinants of objective compliance during oral appliance therapy in patients with sleep-disordered breathing: A prospective clinical trial. JAMA Otolaryngol - Head Neck Surg. 2015;141(10):894-900. doi:10.1001/jamaoto.2015.1756

17. Mifsud M, Molines M, Cases A-S, N'goala G. It's MY health care program: Enhancing patient adherence through psychological ownership. Soc Sci Med. 2019;232:307-315. doi:10.1016/j.socscimed.2019.05.015

18. Kirshenblatt S, Chen H, Dieltjens M, Pliska B, Almeida FR. Adherence to treatment with removable oral appliances: the past and the future. $J$ Can Dent Assoc. 2018;84:i3. http://www.ncbi.nlm.nih.gov/pubmed/31199719. Accessed November 27, 2019.

19. Smith YK, Verrett RG. Evaluation of a novel device for measuring patient compliance with oral appliances in the treatment of obstructive sleep apnea. $J$ Prosthodont. 2014;23(1):31-38. doi:10.1111/jopr.12076

20. Gjerde K, Lehmann S, Naterstad IF, Berge ME, Johansson A. Reliability of an adherence monitoring sensor embedded in an oral appliance used for treatment of obstructive sleep apnoea. J Oral Rehabil. 2018;45(2):110-115. doi:10.1111/joor.12584

21. Chung F, Yegneswaran B, Liao P, et al. STOP Questionnaire: A tool to screen patients for obstructive sleep apnea. Anesthesiology. 2008; 108:812-821.

22. Johns MW. A new method for measuring daytime sleepiness: The Epworth Sleepiness Scale. Sleep. 1991;14(6):540-545. doi:10.1093/sleep/14.6.540

23. Netzer NC, Stoohs RA, Netzer CM, Clark K, Strohl KP. Using the Berlin Questionnaire to identify patients at risk for the sleep apnea syndrome. Ann Intern Med. 1999;131(7):485-491. doi:10.7326/00034819-131-7-199910050-00002
24.

Inoko Y, Yoshimura K, Kato C, Morita O, Kohno M. Efficacy and safety of temperature data loggers in measuring compliance with the use of oral appliances. Sleep Biol Rhythms. 2009;7(3):188-192. doi:10.1111/j.1479-8425.2009.00402.x

25. Dieltjens M, Vanderveken OM, Van Den Bosch D, et al. Impact of type D personality on adherence to oral appliance therapy for sleepdisordered breathing. Sleep Breath. 2013;17(3):985-991. doi:10.1007/s11325-012-0788-x

26. Castillo Y, Blanco-Almazan D, Whitney J, Mersky B, Jane R. Characterization of a tooth microphone coupled to an oral appliance device: A new system for monitoring OSA patients. Annu Int Conf IEEE Eng Med Biol Soc. 2017 July;2017:1543-1546. doi:10.1109/EMBC.2017.8037130

27. Brugarolas R, Valero-Sarmiento JM, Bozkurt A, Essick GK. Autoadjusting mandibular repositioning device for in-home use. Аnпи Int Conf IEEE Eng Med Biol Soc. 2016 Aug;2016:4296-4299. doi:10.1109/EMBC.2016.7591677

28. Khosla S, Deak MC, Gault D, et al. Consumer sleep technology: An American Academy of Sleep Medicine position statement. J Clin Sleep Med. 2018;14(5):877-880. doi:10.5664/jcsm.7128

29. Fitch K, Bernstein SJ, Aguilar MD, et al. The RAND/UCLA Appropriateness Method User's Manual. Santa Monica, CA: RAND Corporation, 2001.

\section{SUBMISSION AND CORRESPONDENCE INFORMATION}

\section{Submitted in final revised form June 10, 2021.}

Address correspondence to: Reza Radmand, DMD; Email: rradmand@BWH.Harvard.edu

\section{DISCLOSURE STATEMENT}

Dr. Galang reports being Secretary-Treasurer of the Illinois Sleep Society. Dr. Rohatgi reports being on an advisory committee for ProSomnus. Dr. Vanderveken reports grants from Inspire Medical Systems, Philips, Somnomed and Nyxoah at Antwerp University Hospital; membership of Advisory Board at Zephyr; Dr. Vanderveken holds a Senior Clinical Fellowship Grant (Fundamenteel Klinisch Mandaat) from Research Foundation - Flanders - Vlaanderen (FWO). 